\title{
UK accident and emergency departments and emergency contraception: what do they think and do?
}

\author{
Babatunde A Gbolade, Max Elstein, David Yates
}

Academic Department of Obstetrics and Gynaecology and Reproductive

Healthcare, University of Manchester,

Manchester

B A Gbolade

Academic Department of Obstetrics and Gynaecology and Reproductive Healthcare, University of Manchester, Manchester and St Mary's Hospital, Manchester

$M$ Elstein

Academic Department of Accident and Emergency Medicine, University of

Manchester and Hope Hospital, Manchester $D$ Yates

Correspondence to: Dr B A Gbolade, Fertility Control Unit, Department of Obstetrics and Gynaecology, St James's University Hospital, Beckett Street, Leeds LS9 7TF.

Accepted 22 October 1998

\begin{abstract}
Objectives-A postal questionnaire survey was conducted to assess what staff in UK accident and emergency (A\&E) departments thought of providing an emergency contraception service, the degree of enthusiasm in and level of provision of the service, and staff attitudes to the introduction or continuation of provision of the service.
\end{abstract}

Methods-A questionnaire was sent to all 560 departments providing $A \& E$ services in the UK.

Results-Of the 560 units sent questionnaires, 355 (63.4\%) replied. Half the units were located in small county towns, and a quarter in large towns. Requests for emergency contraception were received by $96 \%$ of responding units, but only $57 \%$ provided treatment. Requests for emergency contraception in 84 of these units ranged between one and 50 per month. The A\&E senior house officer (SHO) and the gynaecology SHO and registrar prescribed most of the pills. Nurses were more involved in nurse led or general practitioner (GP) led units. Initial treatment only was given by $77 \%$ of providing units while the remainder also discussed subsequent contraception. Follow up was arranged with GPs by 92 units, and with family planning clinics by 66 units. Information packs were available in only 37 providing units. A total of 155 of providing units felt it was worthwhile and $56 \%$ of respondents thought emergency contraception should be provided by $A \& E$ departments. However, 91 units could identify one or more groups within the hospital who were antagonistic to provision by $A \& E$ departments, of which nonA\&E medical staff formed the largest group. Over the counter availability of emergency contraception was not supported by $62 \%$ of respondents.

Conclusion-The results show that while the female population appears to see a need for emergency contraception services to be provided in A\&E departments, there is some reluctance by UK A\&E departments to provide the service. Given the current interest in approaches to reducing unplanned pregnancies, especially in teenagers, provision of emergency contraception by $A \& E$ departments requires a pragmatic approach to ensure their cooperation in providing the service when alternative sources of provision are not available.

(F Accid Emerg Med 1999;16:35-38)

Keywords: emergency contraception; out of hours provision; attitudes of accident and emergency department staff

There is increasing pressure on accident and emergency (A\&E) departments in the UK to provide out of hours emergency contraception services. The standard regimens for emergency contraception are either (a) ethinyloestradiol $100 \mu \mathrm{g}+$ norgestrel $500 \mu \mathrm{g}$ (equivalent to 250 $\mu \mathrm{g}$ levonorgestrel) taken as soon as possible after unprotected sexual intercourse and not later than 72 hours from intercourse, followed by a second dose 12 hours later, or (b) insertion of a copper intrauterine device up to five days after unprotected intercourse. It has been suggested that $A \& E$ departments in the UK should be in the forefront of providing out of hours emergency contraception services because of their 24 hour availability and as a way of helping to meet Health of the Nation targets in reducing unwanted pregnancy. ${ }^{1}$ While it has not been ascertained what UK $A \& E$ departments think of providing the service and if they were willing to provide it, some units are known to have been persuaded by management to provide the service despite reservations by staff.

It was with this background in mind that we decided to undertake a survey of all UK A\&E units in order to assess what they think of providing emergency contraception services, the degree of enthusiasm in and level of provision of the service, and the attitudes of medical and nursing staff to the introduction or continuation of provision of the service in their units.

\section{Method}

Every unit in the UK that provided A\&E services was surveyed in February 1995. A short postal questionnaire with an introductory letter and a reply paid envelope was sent to the person in charge of each unit, asking about their provision of emergency contraception service and their views about certain aspects of provision of the service.

\section{Results}

Of the 560 units sent questionnaires, 355 (63.4\%) replied. Respondents included consultants, general practitioners (GPs), or nurses depending on the size of the unit and who was in charge. Not all the respondents answered 
each question. Calculations were based on the number of respondents to each question. The responses to the questions asked were as follows:

\section{WHERE IS YOUR DEPARTMENT LOCATED?}

About half $(51.3 \%)$ were located in small county towns, a quarter $(25.1 \%)$ were in large towns, and $12.5 \%$ and $11.0 \%$ each were located in suburbs and the "inner city" of metropolitan areas. There was little correlation between location of the unit and whether it provided emergency contraception services.

HOW MANY NEW PATIENTS ATTEND YOUR DEPARTMENT EVERY YEAR?

Eighty six units (25.7\%) saw fewer than 10000 new patients per year; 90 units saw more than 50000 new patients per year. The highest number of new patients seen annually by any one unit was 120000 .

DO YOU RECEIVE ANY REQUESTS FOR EMERGENCY CONTRACEPTION?

Of 351 departments responding to this question, $338(96.3 \%)$ frequently or sometimes received requests while $13(3.7 \%)$ units never received any requests for emergency contraception. Only $84(23.9 \%)$ of those who received requests were able to provide an estimate of the number of requests received. This ranged between one and 50 per month. Seventy four per cent of these units saw between one and 10 patients for emergency contraception per month.

IF YOU RECEIVE A REQUEST FOR EMERGENCY CONTRACEPTION, DO YOU PROVIDE TREATMENT IN YOUR DEPARTMENT?

Of 346 respondents to this question, 198 $(57.2 \%)$ provided emergency contraception when requested.

IF YOU PROVIDE TREATMENT IN YOUR DEPARTMENT WHAT REGIMEN DO YOU USE? All 191 respondents prescribed Yuzpe's regimen (ethinylestradiol $100 \mu \mathrm{g}+$ norgestrel 500 $\mu \mathrm{g}$ (equivalent to $250 \mu \mathrm{g}$ levonorgestrel), 12 hours apart within 72 hours of unprotected intercourse) either using Schering PC4 tablets $(91 \%)$ or Ovran 50 tablets $(9 \%)$. Five units $(1.4 \%)$ also inserted intrauterine devices when appropriate.

WHO ACTUALLY ADMINISTERS THE INITIAL DOSE? The A\&E senior house officer (SHO) and gynaecology SHO and registrar prescribed most of the pills. Consultants were rarely involved. GPs and nurses were more involved in GP or nurse led units.

\section{DOES THE SERVICE IN YOUR DEPARTMENT}

INCLUDE COUNSELLING?

Altogether $150(76.9 \%)$ providing units gave information about initial treatment only. Forty five units provided more detailed service in terms of discussing subsequent contraception and where to obtain more effective methods of contraception.

\section{WHAT ARRANGEMENTS DO YOU MAKE FOR}

FOLLOW UP?

Arrangements for follow up were not uniform among the respondents. Follow up was arranged with only the patient's GP by 92 units and with her GP or family planning clinics by 66 units. Others used a combination of these along with gynaecological outpatient clinics.

DO YOU THINK THIS IS A WORTHWHILE SERVICE IN THE LIGHT OF THE WORKLOAD OF THE A\&E DEPARTMENT?

One hundred and fifty five $(82.9 \%)$ of 187 providing units felt it was a worthwhile service. Common reasons given included the $A \& E$ department being the only outpatient department providing a 24 hour service throughout the year, lack of access to family planning services during weekends and bank holidays, perceived confidential nature of the service provided, youngsters not willing to go to their GPs, and the perceived need to provide this service to people such as visitors and teenagers who would be unwilling or unable to obtain it elsewhere.

Reasons given by providing units with opposite views included the feeling that it was a misuse of $A \& E$ departmental resources to provide the service, it was better provided by GPs and family planning clinics, A\&E departments were already overburdened, and that there was a 72 hour window for hormonal emergency contraception which reduced the need for immediate attention by the department. The design of the questionnaire did not allow non-providing units to express their views as to whether provision of the service was worthwhile or not.

IF YOU DO NOT PROVIDE EMERGENCY CONTRACEPTION, WHERE DO YOU SEND SUCH PATIENTS?

Eighty four (57.5\%) of non-providing units generally referred patients to GPs and family planning clinics. The most common place referred to was the GP $(73.3 \%)$. Others referred to gynaecological wards especially during weekends and to young peoples' drop-in centres.

\section{DO YOU HAVE AN INFORMATION PACK FOR} PATIENTS?

Only 66 providing units had information packs. Thirty seven of the 66 units that had information packs returned copies with the questionnaires. Copies were also returned by three of nine non-providing units that had information packs. The packs contained either leaflets provided by family planning clinics or those designed for the A\&E department.

IF YOU DO NOT HAVE AN INFORMATION PACK, DO YOU THINK THAT AN INFORMATION PACK SHOULD BE PROVIDED?

One hundred and forty four $(60.0 \%)$ of respondents thought that an information pack should be provided. A greater proportion of units that already provided the service than in those that did not, felt an information pack should be provided $(69.0 \%$ compared with $50.0 \%$ ). Common reasons for thinking it 
should be provided were that oral information was apt to be forgotten within a short time, there was inadequate time for counselling and proper instructions, to provide information about where to obtain services, to help in reducing the amount of teaching necessary for proper use, and to explain potential problems associated with use of emergency contraception. Reasons given for objecting to provision of information packs included cost of producing the pack, the fact that packets of Schering PC4 contained information leaflets, leaflets were available from family planning clinics, and that it was not appropriate for the $A \& E$ department.

DO YOU THINK EMERGENCY CONTRACEPTION SHOULD BE PROVIDED IN THE A\&E DEPARTMENT? One hundred and seventy seven (55.8\%) of 317 respondents thought emergency contraception should be provided in the A\&E department. Reasons given were similar to those given for thinking it was a worthwhile service in the light of the workload of the department. Again, a greater proportion of units already providing the service were more favourably disposed to the idea than the proportion of those not already doing so $(78.9 \%$ compared with $28.1 \%$ ). Reasons for thinking it should not be provided included unprotected sexual intercourse being a social problem and not an acute medical problem, adequate family planning services available in the area, lack of adequate time for counselling, feelings of inadequate training to provide service, inadequate opportunities for counselling and follow up, it being inappropriate work for an A\&E department, and the 72 hour window available to obtain hormonal emergency contraception from more appropriate sources, mostly from GPs.

ARE YOU AWARE OF ANY GROUP IN YOUR HOSPITAL WHICH WOULD WISH TO PREVENT THE INTRODUCTION OR CONTINUATION OF THIS SERVICE IN THE A\&E DEPARTMENT?

Ninety one units (42.1\%) of 216 respondents could identify one or more professional groups in the hospital that would wish to prevent the introduction or continuation of the emergency contraception service in the A\&E department. Other medical staff ( 22 units) formed the largest single group identified. In some cases, these included gynaecologists.

DO YOU THINK THIS SERVICE SHOULD BE AVAILABLE OVER THE COUNTER, AT CHEMISTS/PHARMACISTS?

Two hundred and one $(61.7 \%)$ of 326 respondents did not think emergency contraception should be available over the counter. Reasons given for their reservations included pharmacies not being the most conducive place to provide a confidential service, lack of medical input, lack of training of pharmacists to provide necessary counselling and follow up, and availability over the counter would lead to "abuse" of the method and reduction in the use of more reliable methods which may then result in increased number of unplanned pregnancies.

One hundred and twenty five units in favour felt it would reduce the workload of $A \& E$ departments, solve the problem of providing the service out of hours, be convenient, and lead to easy accessibility and that more dangerous drugs were already available over the counter.

\section{Discussion}

A previous survey involving $A \& E$ units in the UK addressed the issue of different policies and practices in postcoital contraceptive provision. ${ }^{2}$ This survey probably assumed the service was voluntarily and enthusiastically provided and compared $200 \mathrm{~A} \& \mathrm{E}$ departments and 200 general practices. A smaller telephone survey in the north west compared the ease with which emergency contraception could be obtained from A\&E departments and GP surgeries from a consumer perspective. ${ }^{3}$ The response rate $(63.4 \%)$ to our survey of $A \& E$ departments is similar to that of Walsh, ${ }^{2}$ although the number of departments involved in our study is greater (335/560 $v 126 / 200)$. It is therefore probably more representative of the views of UK A\&E departments in general, covering the whole range of units by size, location, workload, and staffing levels and patterns.

This study identified the fact that there is no consensus on whether unprotected sexual intercourse constitutes an accident requiring emergency treatment and that there is an appreciable degree of reluctance on the part of UK A\&E departments to provide emergency contraception service. Free text comments in the questionnaires suggested that the willingness to provide the service appeared to be dependent on a multiplicity of interacting factors such as the ethos and leadership of the department, moral attitudes to contraception of the staff in general, and their knowledge about emergency contraception.

The general perception among the respondents appeared to be that unprotected intercourse is not an accident in the real sense of the word and that there is a 72 hour window for the service to be obtained from more appropriate providers. This perception appeared to be shared by clients themselves when asked about their preferred source of obtaining emergency contraception, ${ }^{45}$ and may have been engendered by the experience of previous attempts to obtain the service or the attitudes of A\&E staff. In the light of this perception and the noted degree of reluctance on the part of $A \& E$ departments to provide the service, it was surprising that the majority of respondents were opposed to availability of emergency contraception over the counter at chemists/ pharmacists. This opposition is more difficult to understand in the light of recent increasingly favourable disposition towards over the counter availability of emergency contraception. ${ }^{67}$

There are inherent difficulties in trying to provide an emergency contraception service in $\mathrm{A} \& \mathrm{E}$ departments because of the organisation and nature of work undertaken, staff issues of training and reluctance on personal, religious, 
and moral grounds. In fact, a recent study highlighted the alarming conflict of practice among $A \& E$ consultants that left patients unsure whether they would receive the required help when attending $A \& E$ departments. ${ }^{8}$ Patients may also have reservations about attending the local $A \& E$ unit for the service because they do not feel it is the appropriate place to go. Consideration would therefore need to be given to making the service user friendly and more easily available if it is provided. A recent article highlighted the pivotal part that nurses working in $A \& E$ departments can play in the development and implementation of emergency contraceptive programmes as well as their invaluable contributions as patient educators, advocates, and support persons. ${ }^{9}$

In conclusion, this survey of UK $A \& E$ departments in relation to provision of emergency contraception service revealed that there is some reluctance by $\mathrm{UK} \mathrm{A} \& \mathrm{E}$ departments to provide emergency contraception services. While $96 \%$ of departments receive requests for emergency contraception, only $57 \%$ provide the service. This surely gives the impression that the female population see a need for the service to be provided in these departments. Given the current interest in approaches to reducing unplanned pregnancies, especially in teenagers, the findings of this study argue strongly for an integrated and pragmatic approach which would probably engender increased interest in providing the service among UK A\&E departments. This would be in keeping in keeping with the ethos of the "New NHS". ${ }^{10}$

1 Department of Health. The health of the nation: a strategy for health in England. London: HMSO, 1992

2 Walsh J. Policies and practices in postcoital contraceptive provision: a survey of general practitioners and hospital provision: a survey of general practitioners and hospital Family Planning 1995;20:121-5.

3 Maxwell M, Mooney A, Wilson P. A consumer survey of the availability of hormonal postcoital contraception in the North West region. British fournal of Family Planning 1996 22:79-81.

4 Crosier A. Women's knowledge and awareness of emergency contraception. British fournal of Family Planning 1996;22 $87-90$.

5 Hughes H, Myers P. Women's knowledge and preference about emergency contraception: a survey from a rural general practice. British fournal of Family Planning 1996;22:778 .

6 Glasier A. Emergency contraception: time for deregulation? Br F Obstet Gynaecol 1993;100:611-2.

7 Owen J. Deregulating emergency contraception: justified on current information. BMF 1993;307:695-6.

8 Lindberg CE. Emergency contraception: the nurse's role in providing postcoital options. F Obstet Gynecol Neonatal Nurs 1997;26:145-52.

9 Department of Health. The new NHS: modern, dependable. London: Stationery Office, 1997.

10 Nathan B, Evans G, McKeever J. Practice in prescribing emergency contraceptives in accident and emergency departments varies. BMF 1998;316:148-9. 